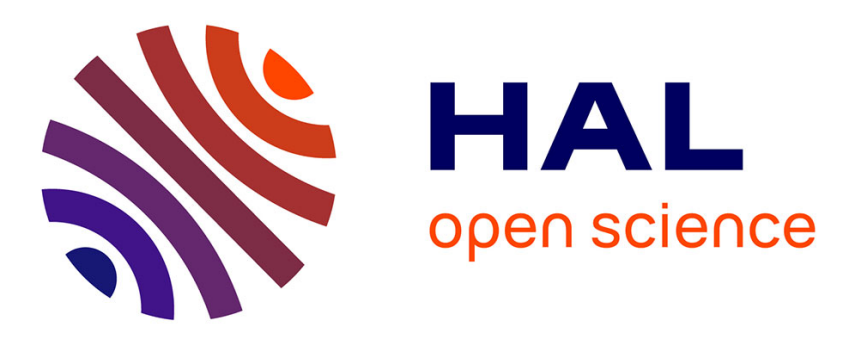

\title{
Observation of surface acoustic wave Brillouin scattering in optical microfibers
}

Jean-Charles Beugnot, Sylvie Lebrun, Gilles Pauliat, Hervé Maillotte, Vincent Laude, Thibaut Sylvestre

\section{- To cite this version:}

Jean-Charles Beugnot, Sylvie Lebrun, Gilles Pauliat, Hervé Maillotte, Vincent Laude, et al.. Observation of surface acoustic wave Brillouin scattering in optical microfibers. Workshop on Specialty Optical Fibers and their Applications, Aug 2013, Sigtuna, Sweden. hal-03223546

\section{HAL Id: hal-03223546 https://hal.science/hal-03223546}

Submitted on 11 May 2021

HAL is a multi-disciplinary open access archive for the deposit and dissemination of scientific research documents, whether they are published or not. The documents may come from teaching and research institutions in France or abroad, or from public or private research centers.
L'archive ouverte pluridisciplinaire HAL, est destinée au dépôt et à la diffusion de documents scientifiques de niveau recherche, publiés ou non, émanant des établissements d'enseignement et de recherche français ou étrangers, des laboratoires publics ou privés. 


\title{
Observation of surface acoustic wave Brillouin scattering in optical microfibers
}

\author{
J-C. Beugnot ${ }^{1}$, S. Lebrun ${ }^{2}$, G. Pauliat ${ }^{2}$, H. Maillotte ${ }^{1}$, V. Laude ${ }^{1}$ and T. Sylvestre ${ }^{1}$ \\ ${ }^{1}$ Institut FEMTO-ST, Université de Franche-Comté, CNRS UMR 6174, Besançon, France \\ ${ }^{2}$ Laboratoire Charles Fabry, Institut d'Optique, Université Paris-Sud, CNRS Palaiseau, France
}

\begin{abstract}
We report the observation of surface-acoustic-wave Brillouin scattering (SAWBS) in a subwavelength-diameter fiber and show that this effect relies on the generation by the electrostrictive force of phonons confined at the surface of the microwire.

OCIS codes: $290.5900,060.4370,160.6030$
\end{abstract}

Brillouin scattering between sound and light waves has been extensively investigated in optical fibers. It is wellknown that silica optical fibers support many transverse and longitudinal elastic waves over a broad frequency range from $50 \mathrm{MHz}$ to $11 \mathrm{GHz}$, that lead to guided-acoustic-wave Brillouin scattering (GAWBS) and stimulated Brillouin scattering (SBS), respectively [1].

In this work, we demonstrate, for the first time to our knowledge, the generation of a new class of surface acoustic waves (SAW) in subwavelength-diameter optical fiber (SDOF) owing to the strong coupling between sound and light at interface between the optical microwire and the surrounding air. These SAW modes or Rayleigh waves cannot be optically excited in standard single-mode fiber (SMF), but they also have recently been evidenced in whispering gallery modes (WGM) microresonators and in silica microspheres [2,3].

In our experiment, we investigated a 8-cm long silica optical microwire drawn from a commercial single-mode fiber (SMF) by hydrogen flame. It has a waist of $1 \mu \mathrm{m}$ and linear losses of $0.1 \mathrm{~dB} / \mathrm{cm}$ at $1.55 \mu \mathrm{m}$. We then performed spontaneous Brillouin backscattering measurements at $1.55 \mu \mathrm{m}$ using a standard heterodyne detection [4]. Figure 1(a) shows the spontaneous Brillouin spectrum for an input CW power of $100 \mathrm{~mW}$. Several peak frequencies with different weights and linewidths can be seen in a frequency range from $6 \mathrm{GHz}$ to $11 \mathrm{GHz}$. The highest frequency peak at $10.86 \mathrm{GHz}$ comes from the standard SBS in the untapered SMF sections of about $2 \mathrm{~m}$ long. We can also observe in Fig. 1(a) three other acoustic frequencies centered at $8.33 \mathrm{GHz}, 9.3 \mathrm{GHz}$ and $10 \mathrm{GHz}$, respectively. Like in SMF, these three acoustic modes exhibit a spectral linewidth around $25 \mathrm{MHz}$ in agreement with the acoustic phonon lifetime in fused silica. Two other acoustic resonances at lower frequencies around $6 \mathrm{GHz}$ can also be observed in Fig. 1(a). To identify the physical origin of these elastic resonances, we performed numerical calculations of the phonon wave packets by solving the elastodynamics equation subject to an electrostrictive force (for detailed calculations, See Refs. [5,6]). With this model, we are able to fully characterize the optoacoustic properties of our silica microwire including both the forward and backward Brillouin spectra without the requirement of a full band structure. We also consider in our model the phonon lifetime by taking into account the elastic losses assuming a complex tensor [7]. This loss model is compatible with the usual assumption that the product of the quality factor $\mathrm{Q}$ and the acoustic frequency is a constant for a given material (e.g., for silica, $\mathrm{Q} \times \mathrm{f}=5$ $\mathrm{THz})$.

Figure 1(b) shows the normalized elastic energy distribution versus the acoustic frequency and for varying the waist diameter from $1 \mu \mathrm{m}$ to $1.35 \mu \mathrm{m}$. The elastic energy distribution gives an overview of the theoretical Brillouin spectrum. As it can be seen, we retrieve most of the acoustic resonances experimentally observed in the waist region of the microwire. There is however a slight difference with experiment in frequency position that can be attributed to the nonuniformity of the microwire, but we can clearly identify the two modes around $6 \mathrm{GHz}$ and the 3 other ones around $9 \mathrm{GHz}$. To go further into detail, we plot in Fig. 1(c) the spatial distribution of the optical mode intensity in the waist region at a wavelength of $1.55 \mu \mathrm{m}$. The black circle marks out the interface between the optical field inside the microwire and the strong evanescent field outside the wire. A large portion of this evanescent field enables the diffusion of light by surface acoustic wave and the highly confined optical field into the microwire induces an electrostrictive force 20 times larger than in SMF [6]. Figure 1(b) shows this electrostrictive force distribution, which was numerically calculated from our model. The kinetic energy density or elastic energy of the two surface acoustic waves at $5.382 \mathrm{GHz}$ and $5.772 \mathrm{GHz}$ are plotted in Figs. 1(e,f) for a waist of $1.05 \mu \mathrm{m}$. The elastic energy is mainly localized at the surface of the microwire, unlike the longitudinal acoustic waves, shown in Figs. 1(g,h), for which the generated phonon wave packet is guided inside the microwire's core by the optical force. 

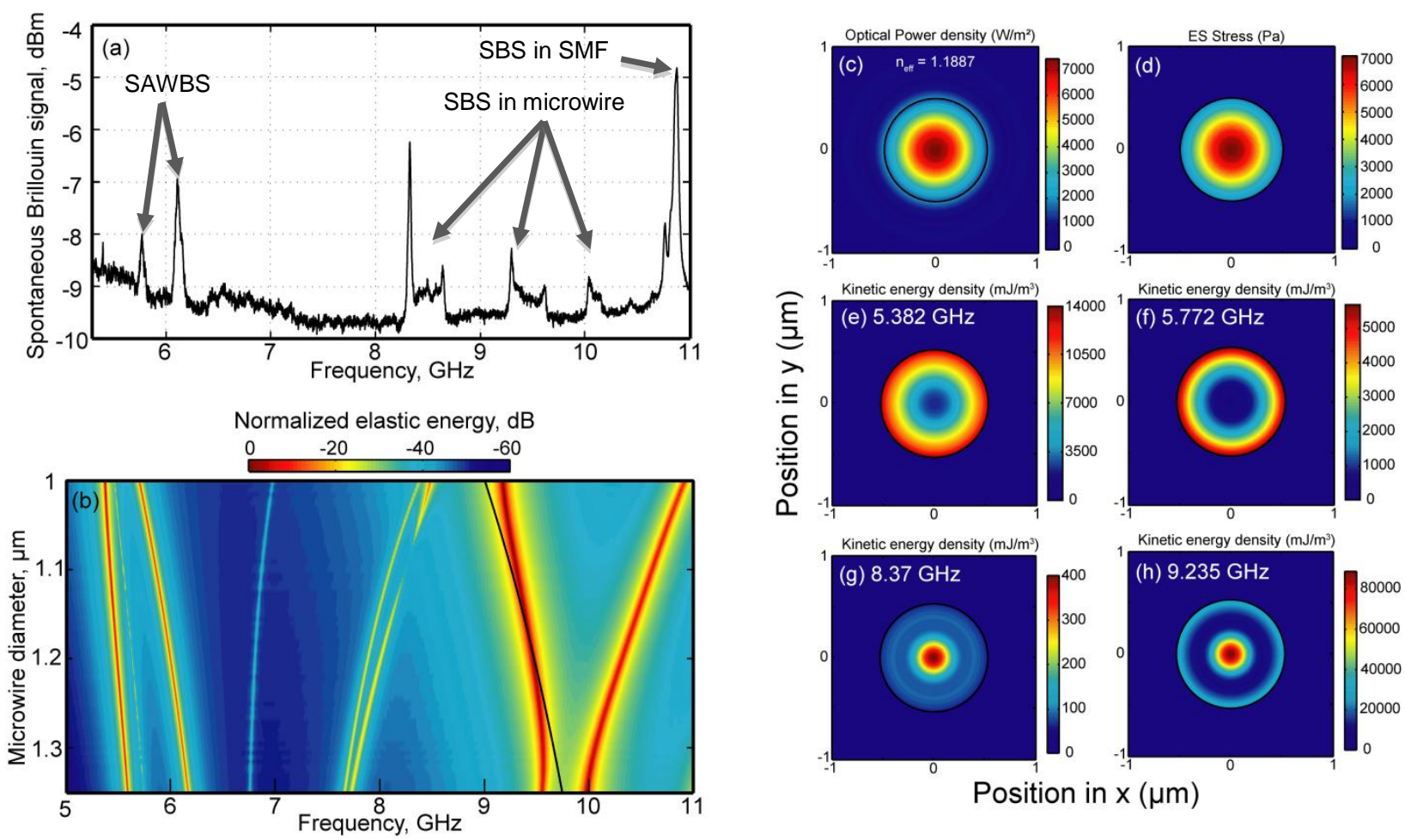

Figure 1: (a) Experimental Brillouin scattering spectrum measured at $1.55 \mu \mathrm{m}$ in 8-cm long silica optical microfiber with a waist of $1 \mu \mathrm{m}$ and for a CW pump power of $100 \mathrm{~mW}$. (b) Computed elastic energy of phonon wave packet (i.e., the theoretical Brillouin spectrum) versus the acoustic frequency and for a microwire waist varying from $1 \mu \mathrm{m}$ to $1.35 \mu \mathrm{m}$. The black line shows the SBS phase-matching condition $(\mathrm{K}=2 \mathrm{Kp})$. (c-g)

Numerical results for a $1.05 \mu \mathrm{m}$ silica rod diameter. (c) Optical power in the fundamental TE-like mode at a wavelength of $1.55 \mu \mathrm{m}\left(\mathrm{n}_{\text {eff }}=\right.$ 1.1887). (d) Spatial distribution of the electrostrictive force with $1 \mathrm{~W}$ optical power. (e,f) Elastic energy density of resonant surface acoustic waves at $5.382 \mathrm{GHz}$ and $5.772 \mathrm{GHz}$, respectively. (g,h) Elastic energy density of longitudinal acoustic modes at $8.37 \mathrm{GHz}$ and $9.235 \mathrm{GHz}$.

Thus these SAW modes can only be excited in sub-wavelength waveguides exhibiting a strong evanescent field. They propagate along the surface with an acoustic velocity of $3410 \mathrm{~m} / \mathrm{s}$, which is lower than both the shear velocity $(3740 \mathrm{~m} / \mathrm{s})$ and the longitudinal velocity $(5960 \mathrm{~m} / \mathrm{s})[7]$.

To summarize, we demonstrated in an optical microfiber with a $1 \mu \mathrm{m}$ waist the efficient generation of surface acoustic wave Brillouin scattering (SAWBS) at new frequency around $6 \mathrm{GHz}$. This work should contribute to a further understanding of the intriguing nonlinear opto-acoustic interactions in sub-wavelength optics. In addition, SAWBS could be used in various sensor applications since the SAW frequency should strongly depend on the material surrounding the optical microwire.

This work is supported by the Université de Franche-Comté and the ANR LABEX ACTION.

\section{References}

[1] G. P. Agrawal, Nonlinear Fiber Optics, $5^{\text {th }}$ Edition, Wiley press, 2012.

[2] A. B. Matsko et al., "Optomechanics with Surface-Acoustic-Wave Whispering-Gallery Modes," Phys. Rev. Lett. 103, 257403 (2009).

[3] G. Bahl et al., "Stimulated optomechanical excitation of surface acoustic waves in a microdevice," Nature Communications 2, 403 (2011).

[4] J-C. Beugnot et al., "Complete experimental characterization of SBS in photonic crystal fiber," Opt. Exp. 15, 15522 (2007).

[5] J-C. Beugnot \& V. Laude, "Electrostriction and guidance of acoustic phonons in optical fibers," Phys. Rev. B 86, 224304 (2012).

[6] V. Laude \& J-C. Beugnot, "Generation of phonons from electrostriction in small-core optical waveguides," AIP Advances 3, 042109 (2013).

[7] R. N. Thurston "Elastic waves in rods and clad rods," J. Acoust. Soc. Am. 64, p. 1-37 (1978). 